\section{A novel influenza A (H1N1) outbreak experience among residents of a long term-care facility in Saudi Arabia during 2010 seasonal flu circulation}

\author{
Raouf M. Affifi, ${ }^{1}$ Sherif R. Omar, ${ }^{2}$ \\ Ahmad A. El Raggal ${ }^{3}$ \\ 'Preventive Medicine Department, \\ Al-Hada and Taif Armed Forces \\ Hospitals, Taif, Saudi Arabia; \\ 2Department of Tropical Health, High \\ Institute of Public Health, University of \\ Alexandria, Egypt; ${ }^{3}$ Preventive Medicine \\ Department, Prince Mansour Hospital, \\ Taif, Saudi Arabia
}

\section{Abstract}

The aim of this work was to describe and analyze an outbreak of novel 2009 influenza A (H1N1) among residents of a long-term care facility (LTCF) in Prince Mansour Military Hospital (PMMH), Taif, Saudi Arabia. These patients had been admitted to the LTCF months or years before the outbreak for several reasons, e.g. cerebral palsy, neurological deficits due to road traffic accidents with resultant handicap, chronic diseases associated with old age. An observational study was carried out to demonstrate and analyze the epidemiological characteristics (demographic factors, risk factors, and outcomes) associated with the outbreak in order to clarify which prevention and control measures had been taken and which recommendations were followed. During the period October 28 to November 11 2010, 21 LTCF residents were suspected to be clinically involved: fever $\geq 38^{\circ} \mathrm{C}$ with influenza-like illness (ILI). Age ranged from 9-91 years (mean $46 \pm 24.13$ ); $62 \%$ were males. Among them, 12 (57\%) were influenza A (H1N1) positive by reverse transcription polymerase chain reaction (RTPCR). Mortality involved 2 (17\%) of the A (H1N1) laboratory confirmed individuals. Implementation of the recommended infection control measures mitigated the transmission of infection to new individuals. The fulfillment of strict infection control measures could limit H1N1 infection among LTCFPMMH patients. Routine influenza, including specific H1N1 immunization of all LTCF residents together with their healthcare staff, should be mandatory in those settings serving immunocompromised patients.

\section{Introduction}

The novel 2009 pandemic influenza A (H1N1) was associated with worldwide outbreaks of febrile respiratory infection. ${ }^{1}$ Although it usually results in a mild illness, several patient groups were at increased risk for complications. ${ }^{2}$ Early in the pandemic, serious steps to deal with a predicted increase in the spread were taken globally. However, after October-November 2010, the overall influenza activity had already declined worldwide. On the other hand, there had been co-circulation of seasonal influenza $B$ viruses, in addition to a post-season rise in influenza A (H3N2) and probably, to a lesser extent, localized outbreaks of influenza A (H1N1). The epidemiological weeks 41 and 42 (10-23 0ctober 2010) showed a total of 1,749 positive specimens of influenza viruses internationally ${ }^{3}$ of which 1,512 (86.4\%) were influenza A and 237 (13.6\%) were influenza B. Also, of sub-type influenzas, 15.6\% were A (H1N1) and $84.0 \%$ were A (H3N2). In LTCFs, outbreaks of influenza are common despite presumed vaccination coverage among residents. According to the clinical practice guidelines of the Infectious Diseases Society of America, an epidemiological investigation should be carried out for such outbreaks and measures taken to prevent the spread of the virus within the institution. ${ }^{4}$ The fragility of patients with debilitating health-conditions, e.g. LTCF patients, to influenza virus outbreaks, and the risk of developing complications, means we must improve our knowledge of the epidemiological characteristics of these small subsets of populations. The current study was designed on the hypothesis that rigorous adherence to strict infection prevention and control measures, including standard and droplet precautions, within a confined longterm care setting could minimize influenza A (H1N1) transmission among exposed individuals. This work aimed to describe and evaluate the epidemiological characteristics of a confined influenza A (H1N1) outbreak that involved a cluster of LTCF residents in PMMH during the 2010 influenza season, and to show the prevention and control measures taken and the recommendations followed.

\section{Materials and Methods}

The study was carried out between October 28 and November 112010 on the wards of the LTCF in PMMH, Taif, KSA. The facility (66 beds) provides care for severely injured, handicapped individuals with crippling physical (and often mental) health problems that make them totally dependent. The outbreak inadvertently coincided with a delay in the supply of
Correspondence: Raouf M. Affifi, Preventive Medicine Department, Armed Forces Hospitals, Taif Region, P.0. Box 1347- Taif, 21944, Saudi Arabia.

E-mail: raoufafifi@hotmail.com

Key words: Influenza A (H1N1), long term-care, outbreak, Saudi Arabia.

Received for publication: 16 November 2011. Revision received: 29 December 2011. Accepted for publication: 8 January 2012.

This work is licensed under a Creative Commons Attribution NonCommercial 3.0 License (CC BYNC 3.0).

(C) Copyright R.M. Affifi et al., 2012

Licensee PAGEPress, Italy

Infectious Disease Reports 2012; 4:e23

doi:10.4081/idr.2012.e23

the H1N1 flu vaccine, mostly due to logistical problems. There was a need to protect LTCF patients and staff against H1N1 infection, especially those who had not been immunized during the 2009 season. Moreover, vaccination was also repeated for pre-immunized individuals to optimize their seroprotection against the H1N1 virus. ${ }^{5}$ Vigilance for early intervention against febrile episodes during the flu season, enforcing intensified infection-prevention and control precautions, conducting prompt surveillance procedures, starting oseltamivir chemoprophylaxis, and wide H1N1 vaccine coverage once available, will all be considered.

The Preventive Medicine Department (PMD) in PMMH was first notified of a febrile episode in 2 LTCF residents on October 28 2010 with ILI, fulfilling suspected H1N1 case definition. The suspected influenza outbreak curve was on the rise over the next five days when the number of subjects with fever went up to 21 (out of a total of 44 patients staying in the facility; patient attack rate $47.7 \%$ ). Together with the hospital services concerned, a surveillance plan was promptly established which included prevention, control, notification and containment measures. The primary aim was to contain the outbreak, and mitigate disease transmission to unaffected patients, staff and visitors. Other objectives regarded minimizing the probability of mainly respiratory complications. Oseltamivir was considered according to the following policy: ${ }^{6,7}$ i) start chemoprophylaxis (75mg twice daily for ten days) for all patients and staff who had not previously received $\mathrm{H} 1 \mathrm{~N} 1$ vaccine; ii) oro- and nasopharyngeal-swabs for febrile patients (see below) for A (H1N1) virus detection; iii) continue oseltamivir for all on the LTCF ward, pending lab results, so that:

patients with confirmed A (H1N1) would 
only complete a five-day medication course, unless a longer course was needed;

withdraw oseltamivir from negative patients who were initially symptomatic;

continue 10-day oseltamivir prophylaxis for non-immunized patients who were not clinically affected.

Other specific prevention and control procedures included: ${ }^{2}$ a) isolation of symptomatic individuals from other patients; b) lab-confirmed cases were considered together while on full treatment; c) reviewing seasonal and H1N1 influenza immunization status of LTCF patients and staff, immunizing those not protected once the specific vaccine was available; d) reinforcing hand hygiene and cough etiquette precautions as appropriate; e) intensified standard and droplet precautions used with infected patients for five days after onset of illness; f) restricting movement of patients, nurses, as well as other health workers, housekeeping, and catering staff between the wings of the facility and access to other hospital premises; $g$ ) restrict entry and exit throughout the LTCF ward to only one access point; $h$ ) temporary closure of the facility to new admissions and visitors on October 28 to minimize virus transmission among patients, followed by gradual release of the ban on visitors guided by daily assessment of outbreak progress; ${ }^{9}$ i) active daily surveillance for all suspected H1N1 patients, including clinical evaluation, vital signs, 02 saturation; and j) close observation of unisolated residents who remained afebrile till the outbreak tapered. ${ }^{10}$

Throughout the outbreak, continuous liaison with the local public health authority was maintained regarding new case notification, lab results and daily case-progress reporting.

This study included 21 LTCF subjects who developed fever with suspected clinical presentation during the course of the outbreak. Inclusion criteria were specific definitions set to verify the study population with respect to type of involvement. ${ }^{11}$ A confirmed H1N1 case means a patient who fell ill and febrile $\left(\geq 38^{\circ} \mathrm{C}\right)$ with positive viral RNA confirmed by real-time reverse-transcription polymerase chain reaction (RT-RTPCR) (see below). A suspected H1N1 case was defined after modification as a patient from the febrile cohort who was epidemiologically linked to a confirmed case. Suspected clinical presentation included the following symptoms and signs: a) fever $\geq 38^{\circ} \mathrm{C}$ (with or without exacerbation of cough and rhinorrhea); or b) fever $\geq 38^{\circ} \mathrm{C}$ plus muscle pain, diarrhea, and/or vomiting; ${ }^{12}$ or c) one or more of the following symptoms: i) dyspnea or difficult breathing; ii) oxygen saturation $\left(\mathrm{O}_{2}\right.$ sat.) at room air (RA) $<90 \%$, or $\mathrm{O}_{2}$ sat. $<93 \%$ on $\mathrm{O}_{2}$ (by mask); iii) respiratory rate (RR) $>30$ cycles per minute (cpm); iv) systolic blood pressure $(\mathrm{SBP})<90 \mathrm{mmHg}$ and/or diastolic
$\mathrm{BP}<60 \mathrm{mmHg}$; v) heart rate $(\mathrm{HR})>120$ beats per minute (bpm) (iii, iv, and v, adults only); vi) severe dehydration (loss of $>10 \%$ of body weight); vii) signs of central nervous system dysfunction, such as altered level of consciousness (e.g. confusion or severe agitation) and seizures; viii) recurrent fever after initial improvement; ix) persistent fever for more than three days not responding to antipyretics excluding other possible causes for pyrexia, and $\mathrm{x}$ ) abnormal or worsening chest X-ray.

Two specimens (oropharyngeal and nasopharyngeal swabs) combined were taken from each patient to collect upper respiratory tract (URT) material to detect the presence of influenza A (H1N1) virus in the patients URT mucosa..$^{13}$ No endotracheal aspirate collection was needed as no patients received intubation. Also, no broncho-alveolar lavage or sputum specimens were collected. The virus isolation samples were taken by assigned PMD staff who applied recommended infection control procedures. This included using personal protective equipment (PPE). ${ }^{14}$ The Vircell ${ }^{\circledast}$ Viral Transport Medium (VTM; ref. MTV001, lot $n$. 09MTV013) kit was used for specimen collection. The assay procedure was performed following the manufacturer's instructions: sample collection with swab, swab put into VTM tube, end of swab stick cut standing out of the tube, taking care not to touch the tube rim, tube closed tightly, patient data filled out, tube immediately placed in a refrigerator at $2-8^{\circ} \mathrm{C}$ for transport to the laboratory via refrigerated delivery at $\left.2-8^{\circ} \mathrm{C}\right) .{ }^{15}$ Samples were often stored at $2-8^{\circ} \mathrm{C}$ overnight until delivered to the laboratory. A real-time polymerase chain reaction (RT-PCR) assay $^{16}$ to confirm influenza A (H1N1) infection was set up on an RT-PCR cycler using primers and a probe set from the Western Province Laboratories, Ministry of Health (MOH), KSA. Equal priority was given to LTCF patients, and swab results were usually reported within 24 hours.

Study variables included: a) demographic criteria, such as age (as an interval ratio scale) and sex; b) diagnostic criteria, including A (H1N1) RT-PCR test (binary: positive/negative); c) outcome data, i.e. survival (binary: lived/died). Potential risk-outcome relationships were studied in attempt to describe the impact of some independent variables (e.g. age, sex) on the H1N1-PCR test status to confirm the pandemic influenza virus infection. In general, the following statistical approaches were used, as appropriate: a) univariate techniques, e.g. $\chi^{2}$ goodness of fit, single-sample t-test, b) bivariate analyses, e.g. independent-samples $\mathrm{t}$-test, $\chi^{2}$ test of independence; c) multivariate techniques, e.g. multiple logistical regression. In the likely event that it was necessary to test the probability of a novel influenza A (H1N1) PCR test result against gender, a $\chi^{2}$ test of independence (or
Fisher's exact test when appropriate) would be performed. In this case, a $\chi^{2}$ test and its $\mathrm{P}$ value or the odds ratio (OR) with $95 \%$ confidence interval (CI) would be used to measure test significance. Likewise, survival would also be analyzed in association with other relevant variables, such as sex and PCR test results (both binary), mostly using $\chi^{2}$ tests with $\mathrm{OR}$ and their $95 \% \mathrm{CI}$ to measure the strengths and stability of these associations. When the normality of age distribution had been ascertained, e.g. using Kolmogorov Smirnov test, a ttest for the differences in the mean ages of the study group variables, e.g. A (H1N1) PCR test and survival outcome, would be calculated. A combination of any two of these risk variables, e.g. H1N1 PCR status by gender or survival status by H1N1 PCR test result would often be sub-analyzed against relevant variables using appropriate statistical techniques. All study data and individual variables were coded and entered into a Microsoft program with adequate backup until analyzed. The SPSS software (version 15) was used to run the selected statistical tests. Tollerance level for $a$ error was $0.05 ; \mathrm{P}<0.05$ was considered significant.

\section{Results}

Twenty-one LTCU residents (13 male, 8 female; male:female ratio 1.6:1) made up the study population. Age of the study population ranged from 9 to 91 years; mean 46 years $( \pm 24.13)$. Patients were stratified into five age categories: $<30,30-39,40-49,50-59, \geq 60$ years. Most patients were in the two most extreme age groups: $28.5 \%$ under 30 years, $33.3 \%$ aged 60 years or over). Nineteen of 21 (90.4\%) patients who were struck by the H1N1 outbreak of LTCF survived the attack compared to 2 (9.6\%) who died; $\chi^{2}$ (1) $13.76, \mathrm{P}=0.0001$.

With respect to laboratory results, 12 of 21 (57.1\%) patients tested H1N1 PCR positive and 9 of $21(42.9 \%)$ patients tested negative $\left(\chi^{2}\right.$ (1) $0.429, \mathrm{P}=0.513)$. Consequently, no significant difference in the frequency of positive versus negative H1N1 PCR tests among individuals who developed similar febrile and/or ILI symptoms was found. However, the tendency of surviving lab-confirmed influenza A (H1N1) was significantly greater than the tendency of fatality among the LTCF patient population; 10 of 12 (83.3\%) vs. 2 of 12 (16.7\%), respectively; $\chi^{2}$ (1) 5.33, P 0.021 .

In order to analyze the relationship between age and H1N1 PCR test results, a t-test was calculated comparing the mean ages for the two H1N1 PCR test groups (PCR-positive/negative). No significant difference in the mean ages between the two groups was found: $t(17.585)=-0.558, \mathrm{P}=0.584$. The mean age for the PCR positive group was 43.42 years \pm SD 
24.77 years, mean age for the PCR negative group was 49.44 years, \pm SD 24.25 years. Age was also analyzed in association with survival and a t-test was calculated to compare mean ages for the outcome groups (survived/died) (Table 1). No significant difference between the mean ages for the two groups was found $(t(19)=1.116, \mathrm{P}=0.278$; mean age of those who survived 47.89 years \pm 24.31 , mean age of the deceased 28.0 years \pm 16.97 ).

The study subjects were further analyzed by gender. There was no significant difference in mean age between the male and female patient groups with suspected $\mathrm{A} / \mathrm{H} 1 \mathrm{~N} 1$ infection: mean age males 52.0 years \pm 21.6 years $\mathrm{SD}$, mean age females 36.3 years \pm 26.3 years $\mathrm{SD}, t(19)=-1.49, \mathrm{P}=0.15$. There was no significant difference in the frequency of PCR positive versus negative results among male and female patients (OR 1.43, CI 0.236, 8.637). Table 2 shows that there was no significant relationship between gender and survival: male survivor 12 of 21 (57.1\%) and male deceased one of 21 (4.8\%) versus female survivor 7 of 21 (33.3\%) and female deceased one of 21 (4.8\%); OR 1.71, CI 0.092-32.25.

\section{Discussion}

On August 10, 2010, Dr. Margaret Chan, WHO Director-General announced that H1N1 influenza virus had moved into the post-pandemic period. ${ }^{17}$ However, localized outbreaks of various magnitudes were likely to continue. As such, our study of H1N1 outbreak actually occurred in the time interval when H1N1 virus had already run its course..$^{18}$ Expectedly, the H1N1 virus would start to behave like a seasonal influenza virus and would continue to circulate for some years to come. In Saudi Arabia, the H1N1 pandemic course was paral- lel to that of the surrounding geographical areas in the northern hemisphere. For instance, until mid-August 2010, only 875 labconfirmed H1N1 cases and zero case-fatalities were reported in Saudi Arabia, compared to more than 17,000 confirmed cases and 124 H1N1-associated deaths through 2009. ${ }^{19}$ During the post-pandemic phase, reported H1N1 incidents were either sporadic cases or limited outbreaks, e.g. boarding institutions, small community settings, etc. Also, of the almost sixty-five million $\mathrm{H} 1 \mathrm{~N} 1$ vaccine doses received worldwide, only 60,000 doses were given in Saudi Arabia from the launch of the global immunization campaign until the time of the study. ${ }^{20}$

There was a relative decline, but not complete disappearance, of the H1N1 pandemic curve. This may have been due to: a) extensive preparedness and support from the international community, e.g. WHO prevention and surveillance plan; b) timely development of a specific H1N1 vaccine, made available for public use shortly after being licensed in midSeptember 2009 (the vaccine proved a good match with the circulating virus and had an excellent safety profile); c) the use of oseltamivir ${ }^{6,7}$ to shorten and limit the disease symptoms and complications; d) the virus did not mutate during the pandemic to a more lethal form; f) widespread resistance to oseltamivir did not develop; ${ }^{18}$ and e) the steady development of herd immunity, either due to mass immunization or widespread natural infection worldwide. Nonetheless, the WHO has issued advice on recommended surveillance, vaccination, and clinical management during the post-pandemic period. ${ }^{17,18}$

Based on available experience from past pandemics, it was likely that the virus would continue to cause serious disease, especially in groups identified during the pandemic to be at higher risk of severe or fatal illness, e.g. LTCF patients. In this study, patient attack rate (47.7\%) was comparable to, for example, that reported in Slovenia (43\%), yet was higher than, for example, that reported in the LTCF outbreaks in Colorado (28\%) and New York (11\%), considering the total bed capacity of each facility (23, 39 and 386 beds, respectively). ${ }^{21,22}$ This LTCF outbreak also had a slightly lower than average duration until the last new case reported compared to the previous studies (7 vs. 8 days). Evidently, the initiation and reinforcement of recommended infection control practices played a role in such a relatively short influenza outbreak attack duration. One limitation of this study was the way in which the influenza virus was introduced into the facility. The virus was often introduced via ill health-care personnel or visitors. However, the role of healthcare personnel in serving as a source of infection could not be proven, especially since no healthcare worker fell ill either before, during or after the outbreak.

On the other hand, some indicators showed the success of the selected preventive measures considered most appropriate for patient

Table 1. Age t-test statistics: age among H1N1- polymerase chain reaction, survival, and gender groups.

\begin{tabular}{lcccc} 
& $t$ & df & Mean age difference & P (two-sided) \\
Age and gender & & & & \\
Age and H1N1-PCR & -1.49 & 19 & $15.9(52.2-36.3)$ & 0.15 \\
\hline Age and survival & -0.558 & 17.585 & $6.03(49.44-43.42)$ & 0.584 \\
\hline
\end{tabular}

PCR, polymerase chain reaction; "Equal variances assumed "Equal variances not assumed.

Table 2. Distribution of outbreak patients by main study variables by gender $(n=21)$.

\begin{tabular}{|c|c|c|c|c|c|c|c|c|c|c|}
\hline & $\begin{array}{c}\text { Male } \\
\mathrm{nl}=13 \\
(61.9 \%)\end{array}$ & $\%$ & $\begin{array}{c}\text { Female } \\
n 2=8 \\
(38.1 \%)\end{array}$ & $\%$ & $\begin{array}{c}\text { Subtotal } \\
{[\mathrm{n} 1+\mathrm{n} 2]} \\
(100 \%)\end{array}$ & $\%$ & Total & $\%$ & OR & $95 \%$ CI \\
\hline \multicolumn{11}{|l|}{ Age Category } \\
\hline Age $<30$ & 2 & 09.5 & 4 & 19.0 & 06 & 28.5 & 21 & 100 & - & - \\
\hline Age 30-39 & 3 & 14.3 & 1 & 04.8 & 04 & 19.1 & & & & \\
\hline Age 40-49 & 2 & 09.5 & 1 & 04.8 & 03 & 14.3 & & & & \\
\hline Age 50-59 & 1 & 04.8 & 0 & 00.0 & 01 & 04.8 & & & & \\
\hline Age $\geq 60$ & 5 & 23.8 & 2 & 09.5 & 07 & 33.3 & & & & \\
\hline \multicolumn{11}{|l|}{ Survival } \\
\hline Survived & 12 & 57.1 & 7 & 33.3 & 19 & 90.4 & 21 & 100 & 1.71 & $0.092,32.25$ \\
\hline Died & 1 & 04.8 & 1 & 04.8 & 02 & 09.6 & & & & \\
\hline \multicolumn{11}{|l|}{ Survival by PCR } \\
\hline Survived $-P C R+v e$ & 6 & 28.6 & 4 & $19 \%$ & 10 & 47.6 & 12 & 50 & 1.5 & $0.071,31.58$ \\
\hline Died -PCR +ve & 1 & 04.8 & 1 & 04.8 & 02 & 09.5 & & & & \\
\hline Survivor -PCR-ve & 6 & 28.6 & 3 & 14.3 & 09 & 42.9 & 09 & 50 & 2.0 & $0.0063,640.9$ \\
\hline Died -PCR -ve & 0 & 0.0 & 0 & 00.0 & 00 & 00.0 & & & & \\
\hline
\end{tabular}

$\mathrm{PCR}$, polymerase chain reaction; OR, odds ratio; CI confidence interval. 
health and outbreak control. Those indicators included: a) steady decline in the disease severity after initiating all infection control precautions previously addressed; b) shortened primary attack rate and the absence of secondary attacks; c) fatalities limited to severely ill patients with a severe underlying crippling health condition; and d) no spread of the disease from the isolation areas to the other facility wards throughout the outbreak.

In this study, no patient, either H1N1-PCR positive or negative, had recurrence of $\mathrm{H} 1 \mathrm{~N} 1$ infection until the end of the 2010 influenza season. In the literature, few data are available on the success of influenza vaccination in mentally and/or physically handicapped children and adults. A recent study by Otsuka and colleagues ${ }^{23}$ showed that the immune response after vaccination depends more on age than on the level and type of physical and mental impairment. Patients in the study of Otsuka et al. were children and adults, yet they failed to develop protection after vaccination. In our study, gender did not impact the attack rate of confirmed H1N1 infection (Table 3). It also did not influence survival, so that both males and females have had the same chance of surviving an influenza outbreak (Table 2). In the similar Slovenian investigation, ${ }^{21}$ March-April 2009, $60.8 \%(\mathrm{n}=23)$ of patients from both sexes (male:female ratio 52.2\%:47.8\%) developed suspected H1N1 symptoms. There was no significant difference in mean age for our male versus female patients (52.0 years \pm 21.6 vs. 36.3 years \pm 26.3 , respectively) compared with those reported in the Slovenian study (22.8 years \pm 5.9 vs. 20.7 years \pm 7.1 , respectively, $\mathrm{P}=0.15$ and 0.46 , respectively) (Table 1 ). We conducted a t-test to compare the mean ages of the male and female patients in the Slovenian study using the published Slovenian data, after assuring normality distribution using Kolmogorov Smirnov test $(\mathrm{P}=0.928)$. No significant difference between the two means was found: $t(20.87)=0.76, \mathrm{P}=0.46$. On the other hand, the attack rate for confirmed H1N1 was higher in the Slovenian males versus females ( 9 of $12=75 \% ; \mathrm{P}<0.05$ ) compared to our study in which no difference was found between the two sexes. No explanation could be found for sex difference in H1N1 lab output in the Slovenian study. On our part, we agree that women may generally mount higher immune responses to viral infections that help have heightened virus clearance. Whether or not such an immunological tendency applies to influenza virus, including novel 2009 H1N1, should be a matter of thorough populationbased research.

Also Fish, in a study which analyzed sex differences in the immune response to influenza viruses, reported that sex has not been systematically examined in those studies handling community-acquired influenza infections. ${ }^{24}$
Furthermore, given the remarkably different mean age in our study (46 years \pm 24.13 ) compared to that of the Slovenian study (21.7 years \pm 6.5 ), as well as the wide difference in the age range profile (9-91 years, range 82 years $v s$. 9-34 years, range 25 years, respectively), a perfectly matched head-to-head comparison could not be made with respect to sex and H1N1 PCR association. Different studies reflecting the experience of other countries with the H1N1 pandemic reported no significant differences according to gender in the number of confirmed 2009-H1N1 cases. . $^{25,26}$

The fact there was no difference in the types of seroconversion among suspected H1N1 patients (Table 4) largely indicates that other influenza subtypes, namely influenza A (H3N2) and/or influenza B viruses, may have contributed to the current outbreak. According to the WHO Influenza update - 8 November $2010,{ }^{3}$ seasonal influenza A (H3N2) viruses continued to be the predominant circulating influenza virus worldwide at that time, alongside co-circulation of seasonal influenza $B$ viruses and, to a lesser extent, influenza H1N1 (2009) viruses. A variation in the rates of H1N1 seroconversion, however, could be found, comparing our investigation with simi-

lar LTCF investigations from the 2009 influenza season: LTCF-PMMH 52\%, LTCF-Slovenia 100\%, LTCF Colorado 27\%, LTCF New York 18\% (including a total number of 21, 10, 11 and 41 ILI patients, respectively).

Also age did not impact influenza A (H1N1) seroconversion or survival potential among our study patients (Table 1). Age could not, therefore, as a ratio scale by a t-test, or categorically by a logistical regression model (data not shown) be used to predict H1N1-PCR test results. Despite the lower risk of infection with $2009 \mathrm{H} 1 \mathrm{~N} 1$ and its unfavorable outcomes among subjects aged 65 years and over compared with seasonal influenza, probably due to the fact that anti-influenza $\mathrm{A}$ antibodies that cross-react with 2009 H1N1 could be detected in up to one-third of healthy adults over the age of $60,{ }^{27}$ all LTCF age groups, including th eelderly, can still suffer 2009 H1N1 outbreaks. ${ }^{28} \mathrm{~A}$ rather benign course throughout the outbreak was seen in the majority of patients (survival rate $90.4 \%$, death rate $9.6 \%$ ). Different death rates have been reported with LTCF influenza A (H1N1) outbreaks elsewhere. In the CDC-led ILI outbreak investigations ${ }^{22}$ between October and November 2009 in three USA states, one patient (33.3\%) in the

Table 3. Distribution of outbreak patients by H1N1- polymerase chain reaction, by gender, by survival $(\mathrm{n}=21)$.

$\begin{array}{lcccc} & \text { n } & \% & \text { OR } & 95 \% \text { CI } \\ \text { H1N1-PCR by gender } & & & & \\ \text { PCR +ve [7/21(33.3\%) male, 5/21 (23.7\%) female] } & 12 & 57.0 \% & 1.43 & 0.236,8.637 \\ \text { PCR -ve [6/21(28.6\%) male, 3/21(14.4\%) female] } & 09 & 43.0 \% & & \\ \text { H1N1-PCR by Survival ( }{ }^{*} \text { ) } & & & & \\ \text { PCR+ve [10/21(47.6\%) survived, 2/21(9.4\%\%) died] } & 12 & 57 \% & 7.2 & 0.102,506.4 \\ \text { PCR - ve [9/21 (43.0\%) survived, 0/21(0.0\%) died] } & 09 & 43 \% & & \\ \text { CR, polymerase chain reaction; OR, odds ratio; CI confidence interval. }{ }^{2} \chi^{2} \text { goodness of fit: survival/PCR +ve group: survived 10/12(83.3\%) vs. }\end{array}$

died 2/12 (16.7\%). [ $\left(\chi^{2}(1)\right.$ 5.33, P 0.021]. Patients with H1N1-infection are more likely to test positive for H1N1-PCR.

Table 4. Distribution of outbreak patients by main study variables $(n=21)$.

\begin{tabular}{|c|c|c|c|c|c|c|}
\hline & N. cases & $\%$ & Total & $\%$ & $x^{2}$ & $\mathbf{P}_{\text {(2-Sided) }}$ \\
\hline $\begin{array}{l}\text { Age category } \\
\text { Age }<30 \\
\text { Age } 30-39 \\
\text { Age 40-49 } \\
\text { Age 50-59 } \\
\text { Age } \geq 60\end{array}$ & $\begin{array}{l}06 \\
04 \\
03 \\
01 \\
07\end{array}$ & $\begin{array}{l}28.5 \\
19.1 \\
14.3 \\
04.8 \\
33.3\end{array}$ & 21 & 100 & - & - \\
\hline $\begin{array}{l}\text { H1N1-PCR result } \\
\text { H1N1-PCR +ve } \\
\text { H1N1-PCR -ve }\end{array}$ & $\begin{array}{l}12 \\
09\end{array}$ & $\begin{array}{l}57.1 \\
42.9\end{array}$ & 21 & 100 & 0.429 & 0.513 \\
\hline $\begin{array}{l}\text { Survival } \\
\text { Survived } \\
\text { Died }\end{array}$ & $\begin{array}{l}19 \\
02\end{array}$ & $\begin{array}{l}90.4 \\
09.6\end{array}$ & 21 & 100 & 1.76 & 0.0001 \\
\hline $\begin{array}{l}\text { Survival by PCR result } \\
\text { Survived }-P C R+v e \\
\text { Died }-P C R+v e \\
\text { Survived -PCR -ve } \\
\text { Died-PCR -ve }\end{array}$ & $\begin{array}{l}10 \\
02 \\
09 \\
00\end{array}$ & $\begin{array}{l}47.6 \\
09.5 \\
42.9 \\
00.0\end{array}$ & 21 & 100 & 1.66 & 0.198 \\
\hline
\end{tabular}

$\mathrm{PCR}$, polymerase chain reaction. 
LTCF in Maine died of respiratory failure secondary to H1N1- infection during the outbreak, in which 7 of 125 residents developed ILI, 3 (43\%) of whom tested H1N1 PCR positive. No H1N1-associatied deaths were reported in the two other participating LTCFs (New York and Colorado) as in the Slovenian investigation. In our study, no difference in the survival rate between H1N1-PCR positive and negativepatients was found.

In conclusion, prompt response to a suspected H1N1 influenza virus outbreak within a long-term care facility, with the aim of rapid detection and containment of virus transmission between exposed individuals, helps improve outbreak outcome. In such a setting in which bed-ridden, physically and mentally handicapped patients constitute a considerable portion of the facility's population at risk, adherence to infection control precautions as prescribed for the H1N1 influenza outbreak is crucial. Since influenza is almost clinically indistinguishable from other respiratory infections, especially in the chesty bed-ridden patients, virological diagnosis, e.g. RT-PCR sub-typing, becomes a prime objective. This helps predict outbreak course and adapt recommended preventive measures. The study results show that reinforcing strict infection control measures pertinent to influenza A (H1N1) during seasonal flu outbreaks at LTCF settings minimizes opportunities for complications to develop and alleviates the disease burden upon the facility and the public health system. The role of seasonal influenza immunization in preventing severe influenza attacks and their unfavorable consequences within the LTCF community should be emphasized. In the presence of a relatively low local H1N1 influenza immunization coverage, including some healthcare workers, an extra effort to enhance the favorable perception of influenza A, including H1N1, and promote immunization of LTCF residents and affiliated staff, is mandatory.

\section{References}

1. World Health Organization (WHO). World now at the start of 2009 influenza pandemic. Available from: http://www.who.int/ mediacentre/news/statements/2009/h1n1_ pandemic_phase6_20090611/en/index.ht ml. Accessed on June 2011.

2. Writing Committee of the WHO Consultation on Clinical Aspects of Pandemic (H1N1) 2009 Influenza. Clinical aspects of pandemic 2009 influenza A (H1N1) virus infection. N Engl J Med 2010;362:1708-19.

3. World Health Organization (WHO). Global Alert and Response (GAR): Influenza Update 120. Available from: http://www. who.int/csr/disease/influenza/2010_11_08
_GIP_surveillance/en/index.html. Accessed on January 2011

4. Harper SA, Bradley JS, Englund JA, et al. Seasonal influenza in adults and children: Diagnosis, treatment, chemoprophylaxis, and institutional outbreak management. Clinical practice guidelines of the Infectious Diseases Society of America. Clin Infect Dis 2009;48:1003-32.

5. Lavallade HD, Garland P, Sekine T, et al. Repeated vaccination is required to optimize seroprotection against $\mathrm{H} 1 \mathrm{~N} 1$ in the immunocompromised host. Haematol 2011;96:307-14.

6. Centers for Disease Control and Prevention (CDC). Recommendations for early empiric antiviral treatment in persons with suspected influenza who are at increased risk of developing severe disease. Health Alert Network (HAN) info service message. Available from: http://www.cdc.gov/h1n1flu/HAN/101909.ht ml. Accessed on January 2011.

7. Centers for Disease Control and Prevention (CDC). Recommendations for use of antiviral medications for the management of influenza in children and adolescents for the 2009-2010 Season: pediatric supplement for health care providers. Available from: http://www.cdc.gov/h1n1flu/ Accessed on January 2011.

8. Centers for Disease Control and Prevention (CDC). Guidelines and recommendations: infection control guidance for the prevention and control of influenza in acute-care facilities. Available from: http://www.cdc.gov/flu/professionals/infectioncontrol/healthcarefacilities.html Accessed on January 2011.

9. Dee S, Jayathissa S. Clinical and epidemiological characteristics of the hospitalized patients due to pandemic H1N1 2009 viral infection: experience at Hutt Hospital, New Zealand. N Z Med J 2010;123:45-53.

10. Infection Control Guidance for 2009 H1N1 Influenza in Long-Term Care Facilities. California Department of Public Health. Available from: http://www.cdph.ca.gov/ HealthInfo/discond/Pages/H1N1CDPHGuid ances.aspx

11. Tang JWT, Tambyah PA, Lai FYL, et al. Differing symptom patterns in early pandemic vs. seasonal influenza infections. Arch Intern Med 2010;170:861-7.

12. Di Giambenedetto S, Verme LZD, Sali M, et al. Clinical presentation, microbiological features and correlates of disease severity of 2009 pandemic influenza A (H1N1) infection. Euro J Clin Microbiol Infect Dis 2011:4:541-9.

13. Centers for Disease Control and Prevention (CDC). Interim Guidance on Specimen Collection, Processing, and Testing for Patients with Suspected Novel
Influenza A/H1N1 Virus Infection. Available from: http:/www.cdc.gov/h1n1flu /specimencollection.html Accessed on: febraury 2011

14. Centers for Disease Control and Prevention (CDC). Interim Guidance on Infection Control Measures for 2009 H1N1 Influenza in Healthcare Settings, Including Protection of Healthcare Personnel. Available from: http://www.cdc. gov/hln1flu/guidelines_infection_control.html Accessed on: January 2011

15. Leonardi GP, Cleaves, CA. Clinical Microbiology Procedures Handbook. Isenberg HD, editor. Washington: American Society for Microbiology;1992.

16. Department of Evaluation, Standards and Training Center for Infections, Health Protection Agency Standards Unit (HPA). Colindale, London, UK. National Standard Method: RT-PCR for the Detection of influenza A Viruses. Available from: http://www.hpa-standardmethods.org.uk/ documents/vsop/pdf/vsop42.p

17. World Health Organization (WHO). H1N1 in the post-pandemic period. DirectorGeneral's opening statement at virtual press conference Available from: http:/ www.who.int/mediacentre/news/statements/2010/h1n1_vpc_20100810/en/index. html Accessed on: March 2011

18. World Health Organization (WHO). Global Alert and Response (GAR). Pandemic (H1N1) 2009 H1N1 now in the post-pandemic period. Available from: http://who. int/csr/disease/swineflu/en/index.html Accessed on: January 2011

19. Ministry of Health (MOH), Kingdom of Saudi Arabia (KSA). MOH, KSA Official Report on the "Fadeout" of 2009-Swine Flu Pandemic. Available from: http://www.moh. gov.sa/Ministry/MediaCenter/News/Pages/ NEWS-2010-8-12-001.aspx Accessed on: January 2011

20. Ministry of Health (MOH), Kingdom of Saudi Arabia (KSA). The MOH, KSA Press Release on A (H1N1) Immunization. Available from: http:/www.moh.gov.sa/ Ministry/ MediaCenter/News/Pages/ NEWS-2010-1-2001.aspx Accessed on: January 2011

21. Socan M, Prosenc K, Tevž-Cizej N. Influenza A (H1N1) outbreak in a long-term care facility for severely handicapped residents, Slovenia, March-April 2009. Euro Surveill 2010;15:19577.

22. Centers for Disease Control and Prevention (CDC). Outbreaks of 2009 pandemic influenza A (H1N1) among longterm-care facility residents-three states, 2009. MMWR 2010;59:74-7.

23. Otsuka T, Fujinaka H, Katsuyama K, et al. Influenza vaccination for severely handicapped persons/children in the 2005-2006 season. Vaccine 2007;25:4521-4. 
24. Fish EN. The X-files in immunity: sexbased differences predispose immune responses. Nat Rev Immunol 2008;8:73744.

25. Belgian Working Group On Influenza $\mathrm{A}(\mathrm{H} 1 \mathrm{~N} 1)$ : Influenza $\mathrm{A}(\mathrm{H} 1 \mathrm{N1})$ virus infections in Belgium, May-June 2009. Euro Surveill 2009;14:19270.
26. European Center for Disease Prevention and Control (ECDC) working group on influenza $A(\mathrm{H} 1 \mathrm{~N} 1)$ : Preliminary analysis of influenza $\mathrm{A}(\mathrm{H} 1 \mathrm{~N} 1)$ individual and aggregated case reports from EU and EFTA countries. Euro Surveill 2009;14:19238.

27. Echevarría-Zuno S, Mejía-Aranguré JM, Mar-Obeso JA, et al. Infection and death from influenza A H1N1 virus in Mexico: a retrospective analysis. Lancet 2009;374: 2072-9.

28. Uyeki, T.M. 2009 H1N1 Virus Transmission and Outbreaks. N Engl J Med 2010;362: 2221-3. 